\title{
Infrared imaging enhances retinal crystals in Bietti's crystalline dystrophy
}

\section{Vikram S Brar \\ William H Benson}

Department of Ophthalmology, Medical College of Virginia Campus, Virginia Commonwealth University School of Medicine, Richmond, VA, USA
Correspondence: Vikram S Brar VCU School of Medicine, Department of Ophthalmology, 40I North I I th Street, Suite 439, Richmond, VA 23298, USA

Email vbrar@mcvh-vcu.edu
This article was published in the following Dove Press journal:

Clinical Ophthalmology

15 April 2015

Number of times this article has been viewed
Abstract: Infrared imaging dramatically increased the number of crystalline deposits visualized compared with clinical examination, standard color fundus photography, and red free imaging in patients with Bietti's crystalline dystrophy. We believe that this imaging modality significantly improves the sensitivity with which these lesions are detected, facilitating earlier diagnosis and may potentially serve as a prognostic indicator when examined over time.

Keywords: Bietti's crystalline dystrophy, infrared imaging, spectral domain optical coherence tomography

\section{Introduction}

Bietti's crystalline dystrophy is a chorioretinal degeneration characterized by the presence of crystalline deposits in the cornea and retina. The latter of which is associated with progressive atrophy of the retinal pigment epithelium (RPE), outer retina, and choriocapillaris. This disease is typically inherited in an autosomal recessive manner, producing symptoms of nyctalopia, visual field loss, and blurred vision starting in the second to third decade of life. This case report demonstrates the superiority of infrared (IR) imaging in demonstrating retinal crystals compared with other modern modalities and conventional fundus photography.

\section{Case description}

We present the case of a 68-year-old African-American female with history of Bietti's crystalline dystrophy. On initial presentation, she reported having difficulty with dark adaptation and driving at night. On more recent visits, she did not endorse symptoms of nyctalopia or visual field loss, despite having serial flash electroretinogram demonstrating progressive reduction in a- and b-wave amplitudes over a 10 -year period. Consecutive Goldmann kinetic visual field testing, over the same time period, revealed constricted III2e and V4e in both eyes. Her past medical history is significant for mitral valve replacement, breast cancer (in remission), diabetes mellitus ( $\times 6$ years, hemoglobin A1c) without retinopathy, and nuclear sclerosis. On further questioning, patient denied use of tamoxifen or tanning agents and any family history of blindness; she does have a family history of glaucoma and vision loss related to complications of diabetic retinopathy.

On examination, her best corrected visual acuities were 20/25 and 20/30. The patient's color vision was evaluated using Ishihara color plates where she scored 8 of 14 in her right eye and 9 of 14 in her left eye. There was no evidence of corneal deposits on slit-lamp evaluation of the anterior segment, although $2+$ nuclear sclerosis was noted. Dilated fundus examination revealed numerous yellow-white retinal deposits and multifocal areas of RPE atrophy in the mid-peripheral fundus of both eyes (Figure 1A). 

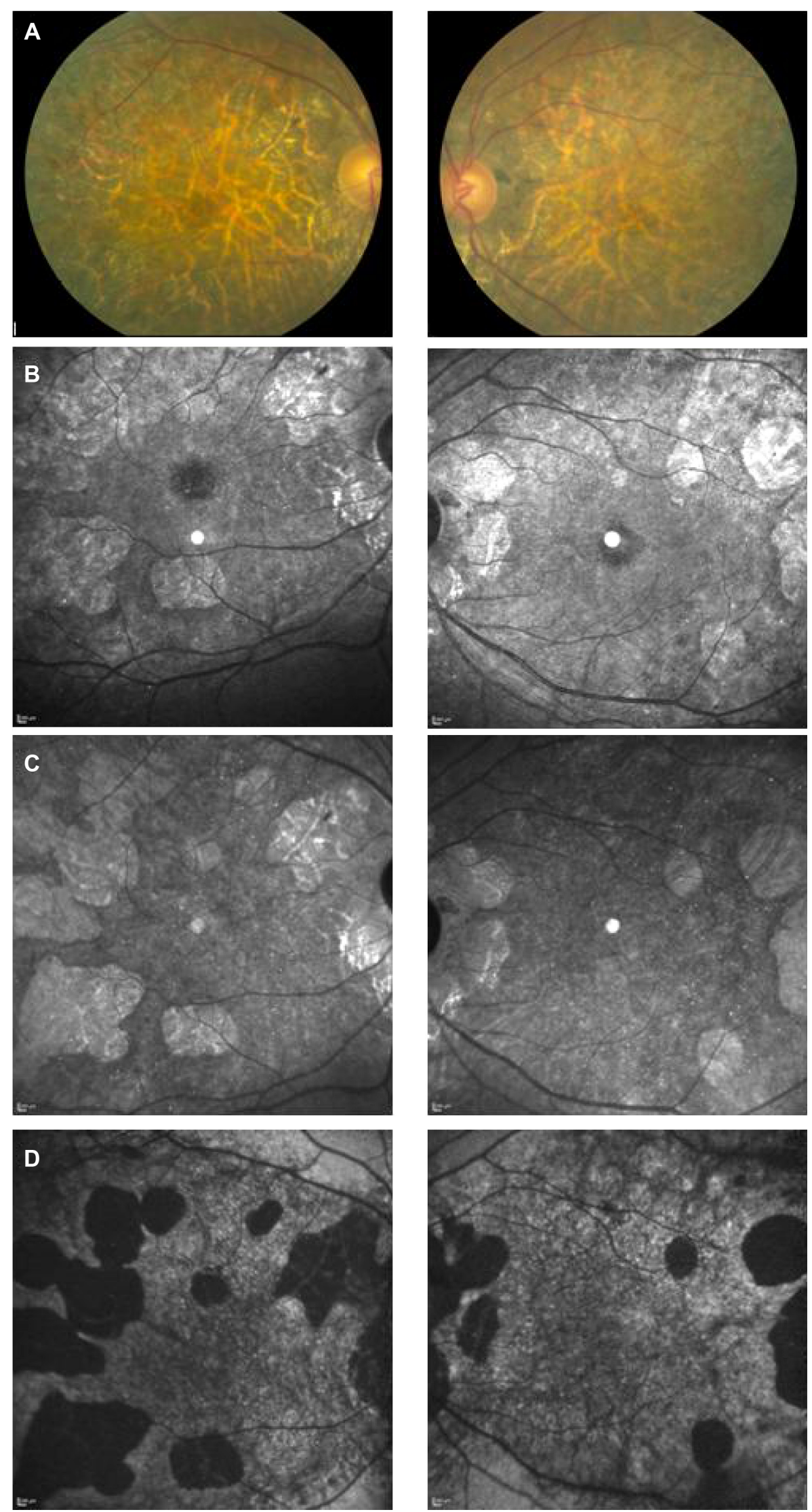

Figure I Fundus imaging.

Notes: (A) Color fundus photograph (Topcon TRC 50EX), (B) red free imaging (Heidelberg Spectralis), (C) infrared imaging (Heidelberg Spectralis), and (D) fundus autofluorescence (Heidelberg Spectralis). 

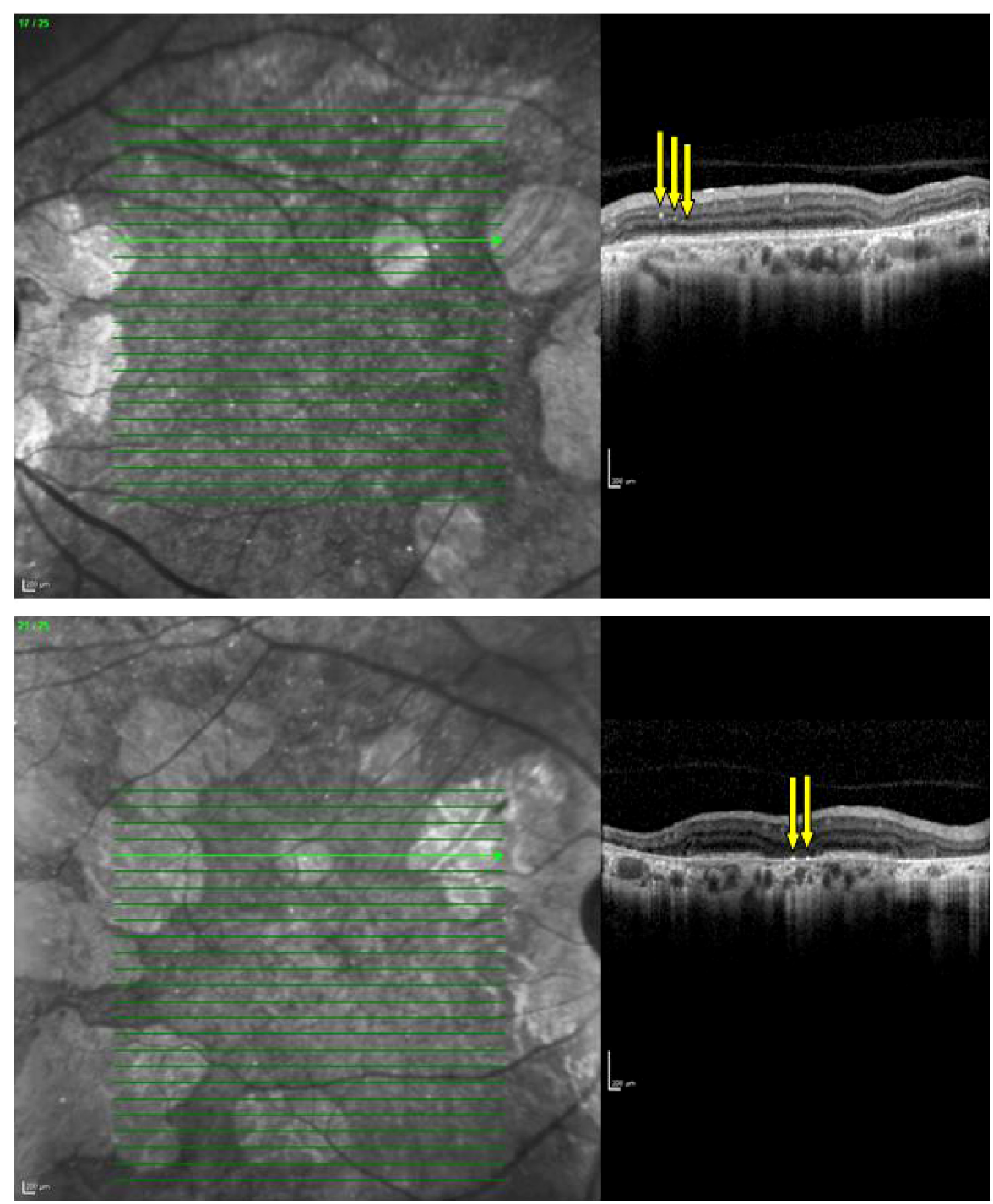

Figure 2 Spectral domain optical coherence tomography images of both eyes through the retinal crystals.

Notes: The yellow arrows demonstrate the location of the crystals in the retina in a region of preserved outer retina (upper panel) and atrophic outer retina (lower panel).

IR imaging demonstrated an increased number of crystals compared with color fundus photography and red free images (Figure 1B and C). Fundus autofluorescence was helpful in highlighting areas of RPE atrophy, which correlated with window defects on fluorescein angiography, but failed to demonstrate crystalline deposits (Figure 1D). Spectral domain optical coherence tomography (OCT) demonstrated areas of extrafoveal outer retinal degeneration and prominent choroidal vascular reflection, correlating with areas of atrophy. Line scans demonstrated hyper-reflective lesions at different layers of the retina (Figure 2).

\section{Comment}

The advent of scanning laser ophthalmoscopic imaging has allowed numerous, simultaneous images of the retina to be obtained in an efficient and a reproducible manner. Prior reports have utilized advanced imaging techniques to describe retinal morphology in patients with Bietti's crystalline dystrophy. ${ }^{2-6}$ All of the information regarding spectral domain OCT describes crystals and other abnormalities primarily in the outer retina, specifically at the level of the RPE. Our case demonstrates crystals in the outer plexiform, inner nuclear, and inner plexiform layers, which are deeper than the standard reflections of inner retinal blood vessels (Figure 2). In review of the OCT images from the literature, the scans obtained represent areas of advanced atrophy where our scans exhibit relatively preserved retina. This difference may account for the distribution of the crystals in our case compared with those published previously, where crystals migrate to the outer retina as they degenerates. 
This report shows the superiority of IR imaging in demonstrating retinal crystals in these patients, compared with clinical examination, color fundus photography, and red free imaging. ${ }^{7}$ In lieu of the paucity of literature describing the uses of IR imaging, it is difficult to postulate the etiology of this difference.

In conclusion, this case report highlights the importance of multimodal evaluation of degenerative retinal disorders. In patients with Bietti's crystalline dystrophy, it supports the role of IR imaging in demonstrating retinal crystals that may facilitate earlier diagnosis of the disease in suspected cases. Larger studies will need to be conducted to confirm this finding and determine its utility over time.

\section{Disclosure}

The authors report no conflicts of interest in this work.

\section{References}

1. Helb HM, Charbel Issa P, Fleckenstein M, et al. Clinical evaluation of simultaneous confocal scanning laser ophthalmoscopy imaging combined with high-resolution, spectral-domain optical coherence tomography. Acta Ophthalmol. 2010;88(8):842-849.
2. Ayata A, Tatlipinar S, Unal M, Ersanli D, Bilge AH. Autofluorescence and OCT features of Bietti's crystalline dystrophy. Br J Ophthalmol. 2008;92(5):718-720.

3. Pennesi ME, Weleber RG. High-resolution optical coherence tomography shows new aspects of Bietti crystalline retinopathy. Retina. 2010; 30(3):531-532.

4. Gaucher D, Saleh M, Sauer A, Bourcier T, Speeg-Schatz C. Spectral OCT analysis in Bietti crystalline dystrophy. Eur J Ophthalmol. 2010; 20(3):612-614.

5. Parravano M, Sciamanna M, Giorno P, Boninfante A, Varano M. Bietti crystalline dystrophy: a morpho-functional evaluation. Doc Ophthalmol. 2012;124(1):73-77.

6. Kojima H, Otani A, Ogino K, et al. Outer retinal circular structures in patients with Bietti crystalline retinopathy. Br J Ophthalmol. 2012; 96(3):390-393.

7. Halford S, Liew G, Mackay DS, et al. Detailed phenotypic and genotypic characterization of Bietti crystalline dystrophy. Ophthalmology. 2014;121(6):1174-1184
Clinical Ophthalmology

\section{Publish your work in this journal}

Clinical Ophthalmology is an international, peer-reviewed journal covering all subspecialties within ophthalmology. Key topics include: Optometry; Visual science; Pharmacology and drug therapy in eye diseases; Basic Sciences; Primary and Secondary eye care; Patient Safety and Quality of Care Improvements. This journal is indexed on

Submit your manuscript here: http://www.dovepress.com/clinical-ophthalmology-journal

\section{Dovepress}

PubMed Central and CAS, and is the official journal of The Society of Clinical Ophthalmology (SCO). The manuscript management system is completely online and includes a very quick and fair peer-review system, which is all easy to use. Visit http://www.dovepress.com/ testimonials.php to read real quotes from published authors. 